\title{
Jorge Luis Borges e Maurice Blanchot: Os pharmakós da escritura
}

Jorge Luis Borges and Maurice Blanchot: Pharmakós of writing

Rodrigo GUimarÃES

Fapemig-Unimontes (Universidade Estadual de Montes Claros-Minas Gerais). Brasil. rodrigo.guima@terra.com.br

\section{RESUMO}

Este artigo analisa os procedimentos desconstrutores efetuados na linguagem, evidenciados na escritura de Jorge Luis Borges e de Maurice Blanchot. Noções tributárias da metafísica ocidental tais como realidade, tempo, espaço, verdade e memória são profundamente desestabilizadas pela textualidade desses escritores.

Palavras chaves: Jorge Luis Borges, Maurice Blanchot, literatura contemporânea, desconstrução.

\begin{abstract}
This essay focuses on the deconstruction procedures accomplished in the language, evidenced in the writing of Jorge Luis Borges and Maurice Blanchot. Notions related to the occidental's metaphysics such as reality, time, space, truth and memory are deeply displaced by the writing of these authors.
\end{abstract}

Keywords: Jorge Luis Borges, Maurice Blanchot, contemporary literature, deconstruction.

\section{RESUMEN}

Este artículo analiza los procedimientos desconstructores efectuados en el lenguaje, evidenciados en la escritura de Jorge Luis Borges y de Maurice Blanchot. Nociones tributarias de la metafísica occidental tales como realidad, tiempo, espacio, verdad y memoria son profundamente desestabilizadas por la textualidad de esos escritores.

Palabras claves: Jorge Luis Borges, Maurice Blanchot, literatura contemporánea, desconstrucción. 
- $\mathrm{m}$ A farmácia de Platão, de Jacques Derrida (2002b), o pharmakós (feiticeiro) Cfoi comparado a um bode expiatório, à alteridade do mal, ao fora. Na Atenas antiga, havia um ritual para expulsar o pharmakós da cidade, a fim de expurgar alguma calamidade que se abatia sobre a região (peste, seca, fome). Não só eram expulsos, mas severamente fustigados em seus órgãos sexuais e depois queimados como forma de purificação do mal. Os pharmakós eram escolhidos entre os homens mais degradados e inúteis. Eram venerados e temidos, benéficos e maléficos; portanto, cercado de precauções. A cerimônia tinha uma data fixa: o sexto dia das Targélias. A menção dessa data não teria importância alguma se não fosse o dia em que nasceu o mais destacado pharmakós da Grécia Antiga: Sócrates.

No Oriente, existiu um outro grande pharmakós da linguagem (lugar de risco para o logos), que viveu supostamente no século dois antes de Cristo: Chuang Tzu (considerado o maior filósofo do taoísmo depois do legendário Lao Tse (VI a.C.). Citado por Derrida, Borges, Haroldo de Campos e muitos outros poetas, Chuang Tzu ficou conhecido por seus textos cujas referências temporais, espaciais, identitárias e lógicas são completamente embaralhadas. Borges se refere a ele em seu texto "Nova refutação do tempo", como aquele que "sonhou que era uma borboleta e, ao acordar, não sabia se era um homem que sonhara ser uma borboleta ou uma borboleta que agora sonhava ser um homem" (Borges, 2000b: 163) ${ }^{1}$.

Todos os pharmakós, de certa maneira, foram desconstrutores, desde que se entenda a desconstrução em seu sentido amplo, qual seja, processo executado na e pela linguagem capaz de deslocar seus próprios fundamentos. Alguns desses escritores foram mais afeitos à formalização, como Derrida, Wittgenstein e Deleuze; outros, mais disseminadores, como Lautréamont, Borges e Blanchot. As operações por eles executadas foram singulares e diversificadas. Lautréamont foi destacado por não ligar bem as frases entre si, pelo esgarçamento do elo lógico entre as sentenças e da dificuldade do leitor em distinguir, em sua escritura, o sério do irônico, o plágio da autenticidade, o Bem do Mal. Ao contrário de Lautréamont, que promove um certo desencaixe entre as sentenças, Jorge Luis

${ }^{1} \mathrm{O}$ belo poema de Borges, "Ein traum", sobre o sonho de Kafka, muito se assemelha às formulaçóes de Chuang Tzu. Entretanto, parece-me que Borges alcançou neste texto uma maior potência desterritorizadora por meio de uma elaboração bem mais intrincada de desdobramentos identitários: "Os três sabiam disso. / Ela era a companheira de Kafka. / Kafka a sonhara. / Os três sabiam disso. / Ele era o amigo de Kafka. / Kafka o sonhara. / Os três sabiam disso. / A mulher disse ao amigo: / Quero que esta noite me queiras. / Os três sabiam disso. / O homem lhe respondeu: Se pecarmos, / Kafka deixará de sonhar-nos. / Alguém soube disso. / Não havia mais ninguém na terra. / Kafka disse a si mesmo: / Agora que os dois partiram, fiquei sozinho. / Deixarei de sonharme" (Borges, 2000c:170). 
Borges produz um texto "clássico", "bem escrito", impecavelmente encadeado, em que o cotidiano se mescla à dimensão fantástica e a ficcionalidade se amalga ao "verossímil".

Com o objetivo de alargar o legado dos textos da desconstrução para além da conceitualidade e dos procedimentos derrideanos, apresentarei dois pharmakós que leram o que nunca foi escrito.

\title{
BORGES E A BIBLIOTECA DE INDECIDÍVEIS
}

\author{
Facilmente aceitamos a realidade, \\ talvez por intuirmos que nada é real. \\ Sonhei a dúvida e a certeza. \\ (Jorge Luis Borges)
}

Poucos escritores no século XX construíram uma biblioteca de indecidíveis (no sentido que lhe confere Derrida) com tanta originalidade quanto Jorge Luis Borges. Referido por muitos como o mestre do labirinto e dos paradoxos, o escritor argentino tornou-se reconhecido mundialmente pelos seus contos e ensaios, em que sobressai uma intrincada trama de caráter ficcional, repleta de citações (nem sempre) apócrifas, fragmentos, alusões mitológicas, referências históricas, filosóficas, literárias e teológicas. Também utiliza o recurso da intratextualidade, em que cita e parafraseia seus próprios textos, tornandose um Outro. Borges escreveu sobre escritores imaginários, fundamentandose em dados históricos falsificados, recorrendo a arquivos inexistentes. Em suma, esmerou-se em desfazer as fronteiras entre o "sonho" e a realidade, em multiplicar as fantasmagorias em sua ilimitada Biblioteca.

Os indecidíveis de sua Biblioteca constituem-se nas mais refinadas desestabilizações de todo um paradigma hegemônico no Ocidente, como as noções usuais que sustentam a metafísica, quais sejam, realidade, tempo, espaço, verdade e memória. Diferentemente de Derrida, que se afeiçoou a desconstruir palavras ou conceitos canônicos do pensamento logocêntrico, Borges desloca todo o bloco do pensamento lógico ao abalar, por meio de paradoxos e outros artifícios, os pilares principais da estrutura da racionalidade. Não recorre à dúvida como método de investigação para alcançar a verdade, como fez Descartes, mas a insere, juntamente com a certeza, no campo ficcional: "Sonhei a dúvida e a certeza". Assim como fez Derrida com a différance, que sustenta a ausência e a presença em seu processo de diferencialidade, Borges alicerça o pensamento do logos em uma base de simulacro. Em outras palavras, não há uma inversão simples do onírico sobrepujando o real, mas ambos se apóiam na ludicidade do jogo que impossibilita até mesmo a localização do 
litoral que separa a realidade da ficção. Em seu conto "Vinte e cinco de agosto, 1983”, Borges encontra Borges num quarto de hotel. Esse outro (ele mesmo) é bem mais velho. Assustado, o narrador (o jovem Borges) pergunta: "Então, tudo isto é um sonho?" A resposta, nada esclarecedora: "É, tenho certeza, meu último sonho". Quem sonha com quem? Esta é a pergunta aristotélica feita pelo jovem Borges. Porém, a resposta é borgeana: "Você não se dá conta de que o fundamental é averiguar se há um único homem sonhando ou dois que sonham um com o outro" (Borges, 2000c: 427).

O duplo, como se sabe, é uma das marcas recorrentes nos contos borgeanos. Difere do par platônico "modelo e cópia”, em que se evidencia a lógica da exclusão, e de um segundo termo decaído. Tampouco se equivale a uma operação de igualdade, os "dois Crátilos" de Sócrates². A perspectiva borgeana insere-se, muitas vezes, em um tipo de lógica dúplice. Portanto, o diálogo do conto "Vinte e cinco de agosto, 1983" transcorre em dois tempos e em dois lugares. Assim entendido, difere também da lógica derrideana do suplemento, visto que não há substituição e adição simultaneamente, mas co-existência e sobreposição de lugares.

Muitas vezes, quando Borges evoca os sonhos, não o faz para destacar apenas a dimensão de oniricidade, e sim de co-existência, de teatralidade, em que muitos lugares são ocupados a um só tempo. Em seu ensaio "O pesadelo", Borges, ao citar Addison, observa que em um sonho "somos o teatro, o auditório, os atores, o argumento, as palavras que ouvimos" (Borges, 2000c: 250).

Quando afirma que a filosofia e a teologia são duas espécies da literatura fantástica, não o faz segundo o propósito de redução ou de ironia. Ao se colocar no fora de uma metaforicidade do lugar, por meio de uma pluralização de operaçóes que se esquivam às topologias biunívocas, Borges interdita o discurso da verdade, seja ele erigido sobre a racionalidade ou por evocação de um empirismo de tipo objetivo ou subjetivo. Em seu conto "O Aleph", vê-se essa atitude de descrédito em relação ao lugar da verdade, da vivência, da plenitude. Após vislumbrar um turbilhão de acontecimentos em uma pequena esfera (um Aleph), localizada no porão de uma casa abandonada, fica maravilhado como as cenas não se sobrepóem e com o fato de que o espaço cósmico estava ali dentro

\footnotetext{
2Sobre a impossibilidade da sobreposição da cópia e do modelo, confira a "indagação" socrática: "Não haveria dois objetos, tais como Crátilo e a imagem de Crátilo, se um deus, não satisfeito em reproduzir apenas tua cor e tua forma, como os pintores, representasse além disso, tal como ele é, todo o interior de tua pessoa, dando exatamente seus caracteres de flacidez e calor, e colocasse nele o movimento, a alma e o pensamento, tais como eles são em ti, em resumo, se todos os traços de tua pessoa, ele dispusesse junto a ti numa cópia fiel? Haveria então Crátilo e uma imagem de Crátilo, ou então dois Crátilos?". Crátilo: "Dois Crátilos, Sócrates, me parece”.
} 
"sem diminuição de tamanho". Contudo, em um "Pós-escrito" seis meses após essa "experiência", o sujeito-narrador faz algumas observações sobre a natureza do Aleph e conclui que se tratava de um falso Aleph. Então, levanta a hipótese da existência (ou que já tenha existido) de um outro Aleph. Ao justificar a sua posição, refere-se a vários outros textos da tradição ocidental e oriental que mencionam artifícios congêneres exercido por espelhos, cálices, lanças, etc. Assim, Borges cria uma rede de simulacros, e o seu Aleph, o da rua Garay, tornase apenas mais um entre tantos. Não há como decidir sobre o verdadeiro Aleph, nem mesmo sobre a autenticidade de seu relato, a pautarmos pela maneira como encerra o conto: "Nossa mente é porosa para o esquecimento; eu mesmo estou falseando e perdendo, sob a trágica erosão dos anos, os traços de Beatriz" (Borges, 2000a: 698).

Ao finalizá-lo dessa forma, Borges convoca mais um de seus indecidíveis, a memória, e recorre à astúcia de simular pequenas incertezas partindo da premissa de que a memória não é precisa e o esquecimento é inventivo. Aliás, em relação à memória, a ensaística borgeana tangencia os dois extremos. Em "O Imortal", ele imagina um mundo sem memória e sem tempo, enquanto que em um de seus contos mais conhecidos, "Funes, o memorioso", constrói um personagem que adquiriu, após um acidente, uma memória e uma percepção infalíveis. Funes não necessita do auxílio da escrita como rememoração. Sua memória é a "memória viva" da qual fala Tamuz, no Fedro de Platão. Ela está em contato direto com a verdade, não a do mundo das idéias do platonismo, mas com a realidade da percepção objetiva e de sua retenção. Funes recorda todas as folhas de uma árvore, "como também cada uma das vezes que a tinha percebido ou imaginado”. A ironia borgeana leva às últimas conseqüências uma representação realista do mundo apoiada em um código único em que cada palavra ou imagem corresponde a um objeto ou situação específica. É a linguagem perfeita sonhada por Leibniz, em que não há ambigüidades ou polissemias na função representativa das palavras. $\mathrm{Ou}$, ainda, de forma menos ingênua, a tentativa de Wittgenstein em Tractatus logico-philosophicus de elaborar uma linguagem proposicional capaz de afigurar o mundo sem as impurezas das tautologias e dos contra-sensos. Contudo, a memória absoluta de Funes não é objeto de admiração do narrador. Ao reverso: "suspeito, entretanto, que não era muito capaz de pensar. Pensar é esquecer diferenças, é generalizar, abstrair" ${ }^{3}$.

${ }^{3}$ Em outros momentos, o narrador descreve a dificuldade de Funes com a linguagem usual: "Não só lhe custava compreender que o símbolo genérico cão abrangesse tantos indivíduos díspares de diversos tamanhos e diversa forma; aborrecia-o que o cão das treze e quatorze (visto de perfil) tivesse o mesmo nome que o cão das treze e quarto (visto de frente). Seu próprio rosto no espelho, suas próprias mãos, surpreendiam-no todas as vezes" (Borges, 2000a: 545). 
Borges não só imprimiu sua marca de indecidibilidade nos temas clássicos, como tempo, espaço, memória e a noção do eu, como também criou um labirinto de paradoxos incomuns e lúdicos. A própria forma de olhar uma moeda, "O Zahir", e ver simultaneamente os dois lados. Não por ele ser transparente, e sim porque o sujeito que olha utiliza uma visão esférica. Ou, ainda, observar que o gigantesco pode ser uma forma do invisível, e por isso não se vê o rosto de Deus, devido ao seu descomunal tamanho: "trezentas e setenta vezes maior que dez mil mundos".

As desconstruções borgeanas, muitas vezes, não passam de falsos paradoxos ou de especulações desconcertantes sobre a linguagem; outras, revestem-se de uma complexa teia de impossibilidades lógicas, como acontece nos contos " $\mathrm{O}$ jardim de veredas que se bifurcam", "O Imortal", "A escrita do Deus" "O livro de areia", "O outro" e "A biblioteca de Babel".

"A biblioteca de Babel", por exemplo, agrega em menos de sete páginas uma refinada trama de paradoxos e especulaçôes inusitadas. Comparada ao universo, ela é formada por "um número indefinido, e talvez infinito, de galerias hexagonais". Os bibliotecários nascem, vivem e morrem sem sair da Biblioteca, imersos em buscas infindas e obsessivas de referências, como o "catálogo dos catálogos", livros de profecias, livros com soluções para todos os problemas pessoais e mundiais. Quanto aos livros, variam imensamente, desde o puro contra-censo, passando pelos enigmáticos (que repetem três letras da primeira à última linha) até os livros de apologias. Segundo o narrador, existem alguns axiomas que dizem respeito à Biblioteca: 1) ela sempre existiu; 2) o número de símbolos ortográficos é vinte e cinco (o ponto, a vírgula, o espaço e as vinte e duas letras do alfabeto). No final do conto, têm-se os seguintes dizeres: "Se um eterno viajante a atravessasse comprovaria ao fim dos séculos que os mesmos volumes se repetem na mesma desordem (que, reiterada, seria uma ordem: a Ordem). Minha solidão alegra-se com essa elegante esperança”’

Vê-se, de passagem, como o pharmakós narrador ordena a desordem por um artifício de retórica, efetua uma passagem rápida da suprema indeterminação para o extremo determinado. $\mathrm{O}$ apelo à repetição, a necessidade de fixar o caos para imobilizar a disseminação do sentido. Só assim a marca se transforma em signo, reiterando-se, atrelando o significante a outro significante, formando uma cadeia, possibilitando um ponto de basta (Lacan) que remete a uma

${ }^{4}$ Segue-se uma nota de rodapé do "próprio" Borges: "Letizia Álvarez de Toledo observou que a vasta Biblioteca é inútil; a rigor, bastaria um único volume, de formato comum, impresso em corpo $\mathrm{dez}$, composto por um número infinito de folhas infinitamente delgadas (...) O manuseio desse vade mecum sedoso não seria cômodo: cada folha aparente se desdobraria em outras análogas; a inconcebível folha central não teria reverso" (Borges, 2000a: 523). 
anterioridade, ao eterno retorno estabelecido tacitamente pela Ordem. Basta soldar as letras e anular o espaçamento, a ilegibilidade.

A personagem borgeana, Letizia Álvarez de Toledo (ver nota 4), propõe um livro somente para representar toda a Biblioteca, desde que tenha o elemento infinitamente delgado da infinitude. Folhas assim tão finas aumentariam a possibilidade de erro, de saltar páginas ao folheá-lo distraído, o que desorganizaria a leitura, a Ordem da Biblioteca. Mas Toledo, ao sugerir que um livro, um único volume, possa representar a Babel e ao resumir em três linhas toda a trama de paradoxos e contra-sensos desenvolvida em sete páginas da "Biblioteca", desconsidera o caráter irredutível da escritura borgeana. A folha central é inconcebível não por não ter reverso, e sim pela impossibilidade de localizar o centro. A palavra errante, diz Blanchot, não é aquela que não tem sentido. Sua errância consiste em ser privada de centro. Um único volume não possibilita as muitas operaçóes com a linguagem presentes na Biblioteca, tais como: não há dois livros idênticos, embora existam centenas de milhares de fac-símiles imperfeitos; tudo que é dado a expressar, em todos os idiomas, está contido nos volumes da Biblioteca; existem milhares de catálogos falsos; cada livro tem uma versão em todas as línguas; e assim sucessivamente.

Borges, o pharmakós, conhece Agripa, o Cético. Já o citou repetidas vezes (para estabelecer uma Ordem?): O Cético "nega que algo possa ser provado, pois toda prova requer uma prova anterior". Sexto Empírico adiciona interstícios de desrazão na tênue arquitetura de uma elegante esperança: "as definições são inúteis, pois seria preciso definir cada uma das palavras utilizadas e, depois, definir a definição". Mas, afinal de contas, estabelecer uma Ordem, por um simples golpe do desejo, não é uma artimanha do pharmakós?

Talvez indagar seja apenas mais uma peça do silêncio.

\title{
BLANCHOT: O DESASTRE COMO ESCRITURA
}

\author{
Assim, nos dissuadindo mais do que nos persuadindo, \\ vêm até nós os textos quebrados de Heráclito. \\ (Blanchot) \\ Ela abrira-se tanto durante o dia \\ que não conseguiu fechar-se de novo à noite. \\ (Rilke)
}

Maurice Blanchot, mesmo antes de sua obra $A$ escrita do desastre, já afirmava que escrever é retirar a palavra do curso do mundo. Observa-se aí uma concepção do desastre como conhecimento, e não do conhecimento como forma de alcançar o desastre. Em certa medida, todos os "desconstrutores" se 
posicionam a favor de algum tipo de operação que possibilita retirar a palavra de seu curso ordinário, embora apresentam diferenças de fatura, pressupostos e encaminhamentos.

Derrida, Deleuze, Borges, Wittgenstein e Blanchot, cada um a seu modo, compartilham uma visão comum que coloca em xeque as verdades metafísicas. Além disso, participam de uma ciranda drummondiana em que Derrida cita Deleuze, que cita Blanchot, que cita Derrida, que cita todo mundo em diálogos subterrâneos ou explícitos. Logo, na lógica dos categoremas, é possível dizer que esses autores se inserem no mesmo paradigma, o da "desconstrução", desestabilizando convenções de diferentes ordem. Entretanto, a desconstrução não pode ser resumida em (pré)posições dissociadas de suas dinâmicas textuais. Se todos assumem um discurso crítico em relação à palavra como representação da realidade, as operaçóes que efetuam com a linguagem diferem entre si de forma significativa. Essa peculiaridade dos procedimentos desconstrutores é irredutível de um autor para outro. Blanchot (ao contrário de Derrida), não evita palavras comprometidas com a conceitualidade metafísica, tais como Ser, centro, essência, neutro, Deus, livro, escritor, obra. Todas elas sugerem uma idéia de totalidade, de unidade semântica. O que é ainda mais perturbador é a freqüência com que aparecem em seus textos denominaçóes que parecem bordejar a lógica aristotélica, na simplicidade do x é y, "avesso" de qualquer abordagem desconstrutora. Tudo isso mesclado de lugares-comuns e uma elevada dose de idealizações sobre a poesia, o poeta, a obra e a literatura. Porém, basta acompanhar de forma mais detida seus textos para constatar uma notável reflexão que adelgaça a espessura ou rompe a suposta integridade desses tecidos e suas nomenclaturas. Em sua obra $O$ espaço literário, é freqüente o movimento, que começa por definições, para, poucas linhas depois, relativizar e, em seguida, contrapor sem reapropriação dialética, sem reconciliação. A título de exemplificação: "o poeta faz obra de pura linguagem e a linguagem nessa obra é retorno à sua essência”. Vê-se aí Blanchot às voltas com o idealismo mais ingênuo tematizando o "retorno à origem". Mas um parágrafo à frente, ao se referir a Mallarmé, Blanchot desconstrói o que acabara de afirmar: "Entretanto, essa poderosa construção da linguagem, esse conjunto calculado para excluir dele o acaso, que subsiste por si só e repousa sobre si mesmo, chamamos-lhe obra e chamamos-lhe ser mas, sob essa perspectiva, não é uma coisa nem outra" (1987: 35) .

Então, pode-se objetar o motivo que levou Blanchot a continuar utilizando as palavras da metafísica clássica, "obra" e "ser", sendo que, muitas vezes, ele

${ }^{5}$ Para Blanchot, o nada mais essencial está entre o Ser e o Nada, é o entre-dois, "um intervalo que sempre se cava e cavando-se se preenche, o nada como obra em movimento" (1969: 35). 
contesta claramente a unidade e a continuidade dessas palavras. É possível indagar: Por que Blanchot não criou um vocabulário específico para lidar com esse pareamento diferencial, assim como fez Derrida?

É justamente aí que o pharmakós atua, pois produz um efeito de grande potência expressiva e desorganizador ao simular que percorre o caminho estabelecido, enquanto, na realidade, escapa a tudo que se sedimentaliza. A farmácia blanchotiana recicla o material da própria casa, reformulando suas maneiras de uso. Gera, em um primeiro momento, um desconforto semântico, para depois saltar para o mal-estar, quando o leitor identifica que as palavras mais familiares, como "dia", "noite" e "neutro", estão fora de lugar. A noite blanchotiana é lugar de (falsos) paradoxos, está sempre próxima mas inaproximável: "é inacessível, porque ter acesso a ela é ter acesso ao exterior, é ficar fora dela e perder para sempre a possibilidade de sair dela" (Blanchot, 1987: 164). Essa noite sem verdade que, no entanto, não mente, só pode estar fora de qualquer formulação proposicional ou de pares opositivos. Para Blanchot, os opostos estão sempre muito próximos um do outro, formando um sistema, uma relação de unidade, enquanto que a diferença entre "o desconhecido e o familiar é infinita". Portanto, a noite não se opõe ao dia, ou, para dizê-lo melhor, ela desdobra-se e estabelece uma relação dessimétrica e irreversível com a outra noite. Da primeira noite se "avizinham" a ausência, o silêncio, o repouso; ou seja, ela não é um ponto morto, o Nada, embora nela se encontre a morte. Entretanto, não se enfatiza uma operação de movimento, como a différance (Derrida), ou de espaçamento, no sentido de Mallarmé, como distanciamento e cálculo atuando na linguagem. A outra noite, que aparentemente se desdobra da primeira, constitui-se do "tudo desapareceu" da primeira noite. A segunda é povoada de sonhos, fantasmas, aparições: "o invisível é então o que não se pode deixar de ver". Blanchot insinua, embora não o diga, que na outra noite as operações de espectralidade são identificadas. A tônica recai em um dinamismo de sobreposições de lugares, no entrechoque das ações que não pertencem aos atos habituais ou inabituais, impossibilitando o encontro da morte e do esquecimento. É a lógica do fantasma, como formula Derrida, no sentido da dupla negação, nem ausente, nem presente, mas suplementada por um anteparo que não a deixa alcançar a pura perda, a dispersão absoluta da morte.

Em outros momentos, Blanchot recorre a um artifício de instauração de paradoxos para depois desativá-los por um processo de abstração que, no final das contas, cessa e cede lugar a uma visibilidade, a explicaçôes que devolvem a "clareza" ao texto. Ao falar daquele que escreve, de sua mão que se move num tempo pouco humano, elabora, de forma quase inapreensível, o belo movimento desse gesto que segura o lápis: "Ela própria sombra de uma mão 
deslizando irrealmente para um objeto convertido em sua sombra" (1987: 15). Por um deslizamento metonímico, muitas páginas depois, Blanchot retoma essa (dupla) mão que escreve na figura do poeta, não mais mediador simplista entre o sagrado e o homem, e sim como um guardião da ausência de Deus, suficientemente atento para nela não se perder ou tampouco a perder. A vigília dessa ausência é um tipo de recusa fundamental para não se deixar reconhecer por sinais "precisos e determináveis", e permitir à literatura o seu estilhaçamento e dispersão, a aproximação "do que escapa à unidade, experiência do que é sem harmonia, sem consenso e sem direito -o erro e o exterior, o inapreensível e o irregular" (1984: 216) ${ }^{6}$.

A dispersão, para Blanchot, nos põe em contato com o "infinitamente movente”. Certamente, a ausência de uma finalidade também perpassa o pensamento blanchotiano, mas ele não o formula assim como o fez Derrida (2002a), que sublinhou a operação da différance como impossibilidade da consumação do telos, do fechamento do processo de significação ou da revelação do ser, dinâmica que se dá em estreita relação com o eixo da temporalização.

Para Blanchot, a questão dita profunda, última, suscitada pela indagação de Deus ou do ser, é um desvio de si próprio, da essência do furtar-se. Entretanto, a palavra como desvio tampouco se rende à definição "o homem é aquilo que se furta” (1984: 59). A relação com a ausência, a palavra como desvio, não prioriza o eixo da temporalizaçãa, tampouco assume o sentido de negação do ser ou da enteidade. Segundo Blanchot, o poema caminha para a ausência, porém sem nunca alcançá-la, pois o que se visa é recompor com ela uma realidade total. Novamente, a escritura blanchotiana sugere a idealidade, para, logo em seguida, desconstruí-la, sendo que a busca dessa totalidade é a condição da poesia, "mas como impossibilidade de sua realização" (1997: 105).

Esse desvio assume a radicalidade que exclui o sujeito da questão, aquele que se coloca na primeira pessoa, assim como impossibilita qualquer dialética ou percepção imediata à maneira de uma participação mística. Essa operação não visa ultrapassar o sujeito e o objeto, o mediato e o imediato, o conhecimento intuitivo e o conhecimento discursivo, mas deixá-los de lado e servir-se do desvio, do que ele tira e póe em reserva, abrindo o acesso ao Outro e interditando qualquer palavra unificadora ou pontificante, no sentido de interligar as margens e apaziguar a estranheza da palavra como desvio, da escrita como desastre.

${ }^{6} \mathrm{O}$ termo dispersão, assim como Blanchot o utiliza, guarda certa proximidade com a disseminação derridiana. No ponto extremo da dispersão "só o lugar se afirma: o nada como lugar onde nada tem lugar" (Blanchot, 1984: 248). No entanto, a dispersão, assim como a disseminação, nunca alcança uma demolição total do sentido, pois a dissolução não dissolve o movimento da dissolução. 
A obra $A$ escrita do desastre é um dos últimos textos de Blanchot, considerado como um dos momentos em que sua escritura atinge a maior força desconstrutora. Blanchot elabora um texto aforístico, fragmentário, com jogos de palavras, citaçóes diretas ou alusões a Derrida, Wittgenstein, Nietzsche, Sartre, Schlegel, Mallarmé, Kafka, Novalis e tantos outros.

Se nas obras anteriores pode-se identificar um resíduo metafísico sobre um pano de fundo idealizador, em $A$ escrita do desastre as antinomias chegam ao extremo, a dispersão parece alcançar o ápice em um texto que alude a Nietzsche no sentido de "aprender a pensar em estado de dor"

O desastre é uma escritura sem lugar e forma de atuação, definitivamente desconstrutora e construtora, posição explicitada logo em sua abertura: "O

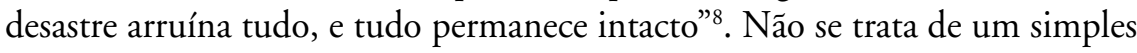
jogo de palavras ou de excesso de paradoxos (embora eles sejam abundantes nesse texto), mas de uma forma de colocar os fragmentos em movimento, entrechocando-se sem a pretensão de desconstruir ou construir o que quer que seja, de inventariar as significaçóes. No entanto, quando lidos isoladamente, os fragmentos são ora desorganizadores, ora afirmativos. Alguns deles lidam com temas prosaicos, como suicídio, amizade, sonhos e ceticismo. Porém, a escritura blanchotiana não os aborda por meio de uma linguagem classicamente organizada, à maneira de Borges. Ao contrário, insere-os em um alto grau de abstração (sustentado por uma referencialidade filosófica extensa e densa, embora entrecortada por outros fragmentos mais coloquiais). Na realidade, essa dinâmica não comporta apenas fragmentos, Blanchot esclarece; ela designa o fragmentário, o movimento que está para além da fratura, do romper-se, da eclosão ou da unidade da parte. Tanto "ter" quanto não ter um sistema é fatal para a mente, observa Maurice Blanchot citando Schlegel. Daí a necessidade de observar essas duas exigências a um só tempo. Esse é o duplo vínculo derrideano (double bind), mas o desastre blanchotiano parece submergir mais profundamente em um campo de abstração e aparente neutralidade: "Existe a questão, mas não desejo de resposta; existe a questão, e nada que pode ser dito, mas justamente esse nada para dizer".

Esse "nada para dizer" evidencia que Blanchot está se referindo a algum tipo de operação com a linguagem, e não ao Nada metafísico, embora esse "não desejo de resposta" parece compor com alguma instância idealizadora. No

" "Learn do think with pain" (Blanchot, 2002). Utilizo aqui a tradução inglesa, sendo que não tive acesso à edição original. Tradução do autor do artigo.

${ }^{8}$ "The disaster ruins everything, all the while leaving everything intact".

9"There is a question, but not desire for an answer; there is a question, and nothing that can be said, but just this nothing, to say" (Blanchot, 2002: 9). 
entanto, existem muitos outros fragmentos que dizem respeito a uma resposta interrogativa ou, ainda, ao desastre como desorganizador do absoluto. Quando Blanchot fala do enigma, por exemplo, não o situa em relação à possibilidade de uma solução, mas como ausência de qualquer resposta: "onde sequer existe espaço para se introduzir a questão" $(2002: 31)^{10}$.

Mas como não reconhecer uma extrema idealização em um fragmento de apenas uma linha que se anuncia como um postulado: "Desprendimento de tudo, inclusive do desprendimento"? Sim, há uma evidência explícita e incontestável nesse fragmento que o insere na tradição idealista ou da mística budista do detachment. Contudo, se forem consideradas as chaves de leitura sugeridas pela própria obra, o fragmento não é o fragmentário; portanto, não pode ser isolado na escrita do desastre. Assim, quando se lê Blanchot pela ótica do fragmento e de sua totalização, corre-se o risco de simplificá-lo em nomenclaturas ou conceitos estabilizadores. Responde o pharmakós: Os "prisioneiros constroem suas próprias prisões. Isto é a culminação do conceito, e o conceito é a marca do sistema" (2002: 45).

\section{REFERENCIAS}

Blanchot, Maurice. 1969. A conversa infinita. Tradução de Aurélio Guerra Neto. São Paulo: Escuta. d'Água.

1984. O livro por vir. Tradução de Maria Regina Louro. Lisboa: Relógio 1987. O espaço literário. Tradução de Álvaro Cabral. Rio de Janeiro:

Rocco.

Rocco.

1997. A parte do fogo. Tradução de Ana Maria Scherer. Rio de Janeiro:

2002. The writing of the disaster. London: University of Nebraska Press. Borges, Jorge Luis. 2000a. Obras completas. São Paulo: Companhia da Letras, V. I. 2000b. Obras completas. São Paulo: Companhia da Letras, V. II. 2000c. Obras completas. São Paulo: Companhia da Letras, V. III.

Campos, Haroldo de. 1993. Metalinguagem e outras metas. São Paulo: Perspectiva. Derrida, Jacques. 2002a. A escritura e a diferença. Tradução de Maria Beatriz Marques Niza da Silva. São Paulo: Perspectiva, tercera edición. 2002b. A farmácia de Platão. Tradução de Rogério Costa. São Paulo: Iluminuras, segunda edición.

${ }^{10} \mathrm{O}$ desastre, diz Blanchot, embora nomeado, não se representa na linguagem (does not figure in language). Mas o desastre não se encontra em um fora absoluto, pois sem a linguagem nada pode ser mostrado, afirma Blanchot. Semelhante formulação estabelece Derrida com a operação da différance. 
Lacan, Jacques. 1998. Escritos. Tradução de Vera Ribeiro. Rio de Janeiro: Zahar. Lautréamont, Conde de. 2005. Os cantos de Maldoror. Tradução de Claudio Willer. São Paulo: Iluminuras.

Wittgenstein, Ludwig. 1979. Investigações filosóficas. São Paulo: Abril Cultural. 